\title{
Factors associated with strain in co-resident spouses of patients following stroke
}

Holly Blake and Nadina B Lincoln School of Psychology, University of Nottingham, Nottingham, UK

Received 15th April 1999; returned for revisions 2nd June 1999; revised manuscript accepted 7th August 1999.

\begin{abstract}
Objective: To identify the factors associated with carer strain following stroke.

Design: Co-resident spouses of stroke patients were sent questionnaire measures of their perceptions of strain, stress, mood, handicap, adjustment, social support, life satisfaction and personality, and patient's mood and independence in activities of daily living.
\end{abstract}

Setting: Stroke spouses were identified from the stroke register at City Hospital, Nottingham.

Results: In a sample of 222 carers, 37\% had significant strain. Strain was highly correlated with negative affectivity on the Positive and Negative Affectivity Scale, carer mood on the General Health Questionnaire-12 (GHQ-12) and carer's perceptions of patient's independence in activities of daily living on the Extended Activities of Daily Living Scale (EADL). Logistic regression analysis of 96 of these carers supported the correlations and showed three factors, carer GHQ-12, patient 
EADL and negative affectivity, were independently associated with carer strain.

Conclusion: The relationship between these factors and strain needs to be tested prospectively. Early identification of carers who may be at risk of strain later on will enable services to be targeted at prevention rather than cure. 


\section{Introduction}

Increases in life expectancy have resulted in a high proportion of elderly people in the population who require informal care. Changes in government health care policy in the UK have shifted attention from institutional to communitybased care. ${ }^{1}$ There are approximately six million carers in Britain - about 2.5 million men and 3.5 million women. Of those carers who are co-resident with the disabled, almost half spend 50 hours a week or more caring and this figure is even higher among carers aged 65 or over. ${ }^{2}$ It is undisputed that caregivers experience significant strain. ${ }^{3}$ Accurate identification of potential stressors, or of carers likely to be unable to cope would enable effective targeting of support to reduce carer strain and help in effectively continuing their role. ${ }^{4}$ Carer strain can reduce the quality of care given to patients ${ }^{5}$ and impact upon physical and psychological well-being. ${ }^{6}$ Care for people with stroke is largely undertaken informally by friends, family or neighbours. ${ }^{7}$ Spouses are more likely than other relatives to provide care at home ${ }^{8}$ and have been identified as the group most at risk from strain. ${ }^{9}$ Personal care may be required, including assistance with washing, bathing, dressing, toileting and incontinence, and physical help such as getting in and out of bed, walking and getting up and down stairs. The spouse may have to adapt to new responsibilities, changes in working life, sex life, finances, social mobility and interpersonal relationships.$^{10}$ There may be depression or anxiety, ${ }^{11,12}$ lack of leisure time, family or marital conflict ${ }^{11,13}$ and loss of sleep. ${ }^{14}$ Carers express fears about the patient having another stroke, having a stroke themselves ${ }^{10,12}$ and of their own, or their partner's death. ${ }^{15}$ 
Strain may also be related to satisfaction with their partner's progress. ${ }^{3}$ These negative impacts of stroke may be long standing. ${ }^{13}$

Thompson et al. ${ }^{16}$ found that physical impairment of the patient was an important predictor of depression amongst caregivers. Previous research showing carer strain focuses primarily on characteristics of the patients. ${ }^{17,18}$ Research that is needed includes characteristics of the carer that may make them more susceptible to strain and psychological distress.

Cantor ${ }^{9}$ suggested that strain is an emotionally laden factor, which is distinct from physical impact on personal life. Certain characteristics of the carer may contribute more to carer strain than environmental and situational changes, or the physical and emotional status of the patient. Particularly relevant are poor carer health and well-being ${ }^{19,20}$ and carer depression. ${ }^{10}$ Carers reported a deterioration in physical health after becoming caregivers. ${ }^{19} \mathrm{Grant}^{20}$ reported a higher frequency of physician visits and use of health services in carers compared with non-caregiving samples. Significant levels of depression have been reported. Schulz et al. ${ }^{12}$ reported depressive symptomology rates two and a half to three times higher than those of non-caregiving samples.

The provision of quantitative data collected using valid and reliable measures will help to identify carers at greatest risk of adverse emotional outcome and therefore those towards which intervention could be targeted. The overall aim of the study was to investigate factors associated with the experience of strain in a group of individuals caring for a partner who had had a stroke. 


\section{Method}

\section{Patients}

All patients admitted to City and University Hospitals, Nottingham, who had had a stroke according to the WHO $(1978)^{21}$ definition were recorded on a register. The patient's name, gender, marital status and admission details were taken from this register.

Co-resident spouses of patients who were recorded consecutively between January 1995 and July 1997 were considered for inclusion in the study. Each patient's general practitioner (GP) was contacted in order to check whether the patient was alive and that their address and marital status had not changed since admission to the hospital. The carers were contacted unless the patient or carer was in hospital, residential care, had died or had moved away. The study had the approval of Nottingham City Hospital Ethics Committee.

\section{Procedure}

Two sets of questionnaires were sent to these carers. Carers were asked to return the questionnaires by post unless the carer required help with the completion of the forms, in which case home visits were made or help was provided over the telephone. Help was given reading the questions or writing the answers, but no extra information was provided, so that data from these questionnaires was comparable to those received through the post. Due to the large number of measures being used, the questionnaires were compiled into 
two forms sent two weeks apart. A covering letter sent with the questionnaire assured the carers that they were under no obligation to complete the form and that not doing so would have no effect on their future care.

Reminder letters were sent to all non-returners and replacement questionnaires sent out where required.

Strain was measured using the Caregiver Strain Index $(\mathrm{CSI})^{3}$ as a brief and easily administered screening instrument for the identification of strain. The CSI contains 13 items related to strain (see Table 4). The scale has established reliability (alpha $=0.86)$ and correlates with patient characteristics, caregiver's subjective perceptions of the caregiving relationship and the physical and emotional health of the caregiver. ${ }^{3}$ The cut- off point for strain of $\geq 7$ was suggested by the author. ${ }^{3}$

Stress was measured using the Perceived Stress Scale (PSS), ${ }^{22}$ which assesses subjective appraisals of stress as opposed to more objective measures of strain or the number of stressful events. This 14-item scale has established reliability $($ alpha $=0.75)$ and correlates with indices of depressive symptomology.${ }^{22}$ Carer mood and carer perceptions of patient mood were measured using the General Health Questionnaire-12 (GHQ-12) ${ }^{23}$ to detect nonpsychotic psychiatric disorder. The London Handicap Scale ${ }^{24}$ was used as a generic health status measure for quantifying disadvantage or 'handicap'. Patients were assessed by carers on the Extended Activities of Daily Living Scale (EADL) ${ }^{25}$ to assess the level of perceived independence in instrumental activities of daily living in 
their partners. The scale incorporates 22 activities in four subsections mobility, domestic, kitchen and leisure. Measurement of carer characteristics included assessment of self-esteem on the Rosenberg Self- Esteem Scale,${ }^{26}$ to measure perceived self-worth as a personal resource.

Attributional style was assessed on the Multi- dimensional Health Locus of Control Scale. ${ }^{27}$ The scale comprises three subscales: 'internality' measures belief in personal control over events, 'chance' measures belief in chance or external factors and 'powerful others' measures belief in the control of powerful others, in particular, health professionals. The Positive and Negative Affect Schedule (PANAS) ${ }^{28}$ was used to assess emotional style or more enduring trait measures of affect in an individuals' predisposition to experience positive or negative mood states. Mood states include anger, disgust, scorn, guilt, fearfulness and depression, or in contrast, level of energy, excitement and enthusiasm.

Emotional control was measured using the Courtauld Emotional Control Scale $(\mathrm{CECS})^{29}$ to assess an individual's tendency to hide feelings versus the tendency to openly express emotions. The CECS has three subsections addressing anger, fear and depression responses. The Life Orientation Test $(\mathrm{LOT})^{30}$ was used to assess dispositional optimism or 'a habitual style of anticipating favourable outcomes'. The higher the score, the more strongly the individual possesses optimism as an enduring personality trait.

Carers' perceptions of their actual and ideal levels of practical and emotional 
informal support from significant others was assessed on the Significant Others Scale. ${ }^{31}$ On this scale a score was obtained for the discrepancy between actual and ideal levels of support, to provide an index of likely satisfaction with the emotional and practical support they receive. Their perception of the amount of formal support they had received was measured on a six-point scale ranging from 'none' to 'a lot'. Carer adjustment was assessed on the eight-item Acceptance of Illness Scale. ${ }^{32}$ The scale was developed for use with patients rather than carers, and so slight alterations to the wording were made to the scale to make it more applicable. For example, 'Because of my health I miss the things I like to do most' became, 'Because of my partner's health I miss the things I like to do most'. Overall satisfaction with life was measured using the five-item Satisfaction with Life Scale (SWLS). ${ }^{33}$

\section{Results}

There were 1350 patients on the Stroke Register who had had a stroke between January 1995 and July 1997, of whom 465 patients had an identifiable coresident spouse. The first questionnaire was sent to these 465 carers. Of these, 227 (49\%) were returned, of which five were incomplete and $222(48 \%)$ were available for analysis. Of these carers, 74 (33\%) were men and $148(67 \%)$ were women. Patient ages ranged from 35 to 91 years (mean 71, SD 10.34). These 222 carers were sent the second questionnaire. Of these, 97 (44\%) were returned, of which one was incomplete and 96 (43\%) were available for analysis. Of these carers, $30(31 \%)$ were men and $66(69 \%)$ were women. 
Patient ages ranged from 35 to 91 years (mean 69, SD 11.16).

Of 222 respondents, $82(37 \%)$ scored equal to or above 7 on the $\mathrm{CSI}^{3}$ indicating significant strain. There were no significant differences between men and women carers in strain (Mann-Whitney $U=5666, p=0.84)$. The distribution of scores on each measure is shown in Table 1.

As the data were predominantly ordinal, non- parametric analysis was used. Spearman's correlation coefficients were calculated between strain and each of the questionnaire measures. Results are shown in Table 2. CSI was not significantly correlated with age of the patient or time since stroke. A high level of strain was associated with low mood in the carer, low perceived mood and EADL (kitchen, domestic, leisure and mobility) in the patient and increased handicap of the carer. The CSI was not significantly related to emotional expressivity or internal or powerful others health locus of control. Strained carers had significantly lower self-esteem, decreased positive affectivity and increased negative affectivity. Increased strain was significantly related to lower levels of dispositional optimism and adjustment to the stroke. Those carers who were more strained perceived themselves as receiving significantly less actual emotional and practical support from informal sources and this was related to a greater discrepancy between their actual level of emotional and practical informal support and what they perceived to be their ideal. There was no significant relationship between CSI and ideal levels of emotional or practical support. High levels of carer strain were associated with 
higher levels of support from formal services and less satisfaction with their lives.

The 15 variables that were not significantly correlated at $p$ " 0.001 were removed from consideration in the following analysis to ensure that large numbers of variables weakly or not at all associated with carer strain did not reduce opportunities to find more global effects. Logistic regression with forward selection was carried out on the 96 patients for whom all variables were available with strain as the dependent variable.

The logistic regression model for strain showed that strain on the CSI was best predicted by carer mood. Other predictors of strain significant in the equation were perceived patient EADL and negative affectivity. No other variables were significant in the model. Results are shown in Table 3. The predictive equation from the logistic regression was $75 \%$ accurate in classifying carers into those who were strained and those who were not.

If each item on the Caregiver Strain Index con- tributes an equal amount to whether a carer is strained or not strained, then the distribution of yes/no answers in the 'strained' group of carers should be comparable to the distribution of yes/no answers in the 'not strained' group. Detailed analysis of the distribution of answers for each question may reveal which factors contribute the most to carer strain. Results are shown in Table 4.

The chi-squared test was used to test the null hypothesis that the level of strain the carer experiences is independent of yes/no answers for each item on the 
CSI. Strain yes/no was cross-tabulated against each item of the CSI.

Chi-squared was significant between overall strain and disturbed sleep, inconvenience, physical strain and whether caring was confining. Overall, chisquared was significant between strain and family changes, changes in personal plans, whether there were other demands on the carer's time, emotional adjustments, upsetting behaviour and whether or not the carer thought that their partner had changed. There was a significant chi-squared between strain and work adjustments, financial strain and whether the carer felt overwhelmed.

Chi-squared was significant for each item on the CSI. This suggests that overall strain is distributed evenly across each item of the CSI and that each item contributes to the overall level of strain experienced.

\section{Discussion}

The most important factor associated with strain experienced by the co-resident spouse caregivers of stroke patients was carer mood. These results provide support for previous research. ${ }^{3}$ Consistent with other research, ${ }^{16}$ a significant relation- ship was found between carer strain and level of disability of the patient in extended activities of daily living. The third strongest factor associated with strain was negative affectivity in the carer. Although correlated with low mood, negative affectivity refers to a general, enduring trait mea- sure as opposed to a transient mood state and thus may not be as amenable to change. 
The logistic regression analysis indicated that the factors significantly associated with strain were independently associated and the correlations were not significant simply because they correlated with each other. The advantage of logistic regression is that it takes account of inter-dependency between variables.

The results reported here are applicable to the co-resident spouse caregivers of stroke patients. In the pilot study only $10 \%$ of the carers completed a question on age and so this was removed from the form. Although not ideal, it was assumed that the carers, as co-resident spouses, would represent a similar age distribution to the patients with whom they cohabited. Caregiver age may influence variables such as psychological and physical health outcomes. ${ }^{19}$ However, patient age was not a significant factor in the regression equation. There were also no data available on patient incontinence, which is a factor that may affect the level of strain experienced.

Respondents needed to be literate in English to complete the assessments, which may have excluded carers from some cultural backgrounds. It was not possible, therefore, to analyse patterns of perceptions of caregiving across cultures. Furthermore, co-resident caregivers may be more motivated and positive towards caregiving than carers who are not co-resident and so the results may not be applicable to carers of other relationships and living arrangements. The response rate in the study was relatively poor and therefore the results may not represent stroke spouses as a whole. The poor response rate 
resulted in a large number of measures with a relatively modest sample size. It would be useful to compare characteristics of responders with non-responders; however, this information was not available here. The non-significance of time since stroke may be a result of possible under-representation of the longer times due to exclusion of those in hospital, residential or nursing homes or those who had moved away.

The hypothesis that strain is most strongly associated with carer mood, patient disability and negative affectivity needs to be tested prospectively. Early identification of low mood in the carers might enable early identification of those carers who will cope effectively with their partner's illness and those who will experience great distress. However, it is necessary to test whether the associations identified here hold across time, in order to determine whether early identification of later strain is possible.

This may have implications for service provision. Since the majority of existing community intervention services are initiated in response to a crisis situation, such as the breakdown of physical and psychological well-being after a partner has suffered a stroke,${ }^{6}$ it might be feasible to target services towards prevention as opposed to cure.

\section{Acknowledgements}

The authors would like to thank all the carers who participated in the study and Professor P Fentem of Stroke Medicine, Nottingham City Hospital, for financial support. 


\section{Clinical messages}

- Co-resident spouses of stroke patients experience significant strain on the Caregiver Strain Index (CSI).

- Strain is most strongly associated with mood, perceived patient Extended Activities of Daily Living (EADL) and negative affectivity these factors can now be tested prospectively.

- Early identification of carers at risk of strain later on means services can be targeted at prevention rather than cure.

\section{References}

1 Haug MR. Home care for the ill elderly: who benefits? Am J Public Health 1985;

75: $127-28$.

2 Lewycka M. Survival skills for carers: a resource pack for trainers. National Extension College Trust, Ltd., 1993.

3 Robinson BC. Validation of a Caregiver Strain Index. J Gerontol 1983; 38: 34448.

4 Sandin KJ, Cifu DX, Noll SF. Stroke rehabilitation 4. Psychologic and social implications. Arch Phys Med Rehabil 1994; 75: 552-55.

5 Glass TA, Matchar DB, Belyea M, Feussner JR. Impact of social support on 
outcome from stroke. Stroke 1993; 24: 64-70.

6 Warburton RW. Implementing caring for people: home and away. London:

Department of Health, HMSO, 1994.

7 Twigg J. Carers: research and practice. London: HMSO, 1992.

8 Zarit SH, Edwards AB. Family caregiving: research and clinical intervention. In: Woods RT ed. Hand- book of the clinical psychology of ageing. Chichester: John Wiley \& Sons, 1996.

9 Cantor MH. Strain among caregivers: a study of experience in the United States. The Gerontologist 1983; 23: 597-604.

10 Holbrook M. Stroke: social and emotional outcome. J R Coll Physicians Lond 1982; 16:100-30.

11 Anderson CS, Linto J, Stewart-Wynne EG. A population-based assessment of the impact and burden of caregiving for long-term stroke survivors. Stroke 1995; 26: $843-49$.

12 Schulz R, Tomkins CA, Rau MT. A longitudinal study of the psychosocial impact of stroke on primary support persons. Psychol Ageing 1988; 3: 131-41.

13 Kinsella GJ, Duffy FD. Psychosocial readjustment in the spouses of aphasic patients. Scand J Rehabil Med 1979; 11: 129-32.

14 Sanford JRA. Tolerance of debility in elderly dependents by supporters at home: its significance for hospital practice. BMJ 1975; 3: 471-73.

15 Anderson R. The aftermath of stroke. Cambridge: Cambridge University Press, 
1992.

16 Thompson SC, Sobolew-Shubin A, Graham MA, Janigian AS. Psychosocial adjustment following a stroke. Soc Sci Med 1989; 28: 239-47.

17 Lincoln NB, Willis D, Philips SA, Juby LC, Berman P. Comparison of rehabilitation practice on hospital wards for stroke patients. Stroke 1996; 27: 18-23.

18 Lincoln NB, Gladman JRF, Berman P, Luther A, Challen K. Rehabilitation needs of community stroke patients. Disabil Rehabil 1998; 20: 457-63.

19 Elmstahl S, Malmberg B, Annerstedt L. Caregiver's burden of patients 3 years after stroke assessed by a novel caregiver burden scale. Arch Phys Med Rehabil 1996; 77: $177-82$.

20 Grant JS. Home care problems experienced by stroke survivors and their family caregivers. Home Healthcare Nurse 1996; 14: 892-902.

21 WHO (World Health Organization). Cerebrovascular disease: a clinical and research classification. WHO offset series no. 43. Geneva: WHO, 1978.

22 Cohen S, Kamarck T, Mermelstein R. A global measure of perceived stress. $J$ Health Soc Behav 1983; 24: 385-96.

23 Goldberg D. General Health Questionnaire (GHQ-12). Windsor: NFER-Nelson, 1992.

24 Harwood RH, Rogers A, Dickinson E, Ebrahim S. Measuring handicap: the London Handicap Scale, a new outcome measure for chronic disease. Qual Health 
Care 1994; 3: 11-16.

25 Nouri FM, Lincoln NB. An extended activities of daily living scale for stroke patients. Clin Rehabil 1987; 1: 301-305.

26 Rosenberg M. Society and the adolescent self-image, reprint edition. Middletown,

CT: Wesleyan University Press, 1989.

27 Wallston KA, Wallston BS, DeVillis R. Development of the Multidimensional Health Locus of Control (MHLC) Scales. Health Educ Monographs 1978; 6: 161-70.

28 Watson D, Clark LA, Tellegen A. Development and validation of brief measures of positive and negative affect: The PANAS scales. J Pers Soc Psychol 1988; 54: $1063-70$.

29 Watson M, Greer S. Development of a questionnaire measure of emotional control. J Psychosom Res 1983; 27: 299-305.

30 Scheier MF, Carver CS. Dispositional optimism and physical well-being: the influence of generalised outcome expectancies on health. J Pers 1987; 5: 169-210.

31 Power MJ, Champion LA, Aris SJ. The development of a measure of social support: the Significant Others Scale (SOS). Br J Clin Psychol 1988; 27: 349-58.

32 Felton BJ, Revenson TA, Hinrichson GA. Stress and coping in the explanation of psychological adjustment among chronically ill adults. Soc Sci Med 1984; 18: 88998.

33 Deiner E, Emmons RA, Larson RJ, Griffin S. The Satisfaction with Life Scale. $J$ Pers Assess 1985; 49: 71-76. 
Table 1 Distribution of scores for each variable (medianfinterquartile range)

\begin{tabular}{|c|c|c|c|c|}
\hline Variable & Possible range & $n$ & Median & IOR \\
\hline Age of patient (years) & - & 222 & 71 & $64-77$ \\
\hline Days since stroke & - & 222 & 530 & $248-730$ \\
\hline London Handicap & $0-100$ & 222 & 68 & $55-81$ \\
\hline Occupation & $0-6$ & 222 & 3 & $2-5$ \\
\hline Orientation & $0-6$ & 222 & 1 & $1-2$ \\
\hline Independence & $0-6$ & 222 & 2 & $1-4$ \\
\hline Mobility & $0-6$ & 222 & 3 & $2-3$ \\
\hline Economic self-sufficiency & $0-6$ & 222 & 2 & $2-4$ \\
\hline Social integration & $0-6$ & 222 & 2 & $2-3$ \\
\hline Patient EADL & $0-22$ & 222 & 7 & $3-14$ \\
\hline Kitchen & $0-5$ & 222 & 3 & $1-5$ \\
\hline Domestic & $0-6$ & 222 & 2 & $0-2$ \\
\hline Mobility & $0-6$ & 222 & 2 & $0-5$ \\
\hline Leisure & $0-5$ & 222 & 2 & $1-3$ \\
\hline Carer GHQ-12 & $0-12$ & 222 & 3 & $1-6$ \\
\hline Patient GHQ-12 & $0-12$ & 222 & 4 & $1-7$ \\
\hline Internal HLC & $6-36$ & 96 & 23 & $19-27$ \\
\hline Chance HLC & $6-36$ & 96 & 19 & $14-22$ \\
\hline Powerful HLC & $6-36$ & 96 & 21 & $18-26$ \\
\hline CECS total expressivity ${ }^{*}$ & $21-84$ & 96 & 57 & $48-63$ \\
\hline CECS anger ${ }^{\circ}$ & $7-28$ & 96 & 17 & $14-22$ \\
\hline CECS depression ${ }^{\circ}$ & $7-28$ & 96 & 20 & $16-23$ \\
\hline CECS fear ${ }^{\circ}$ & $7-28$ & 96 & 940 & $16-21$ \\
\hline Life orientation test & $0-48$ & 96 & 17 & $13-21$ \\
\hline Negative affectivity" & $10-50$ & 96 & 20 & $14-29$ \\
\hline Positive affectivity & $10-50$ & 96 & 32 & $26-37$ \\
\hline Rosenberg self-esteem scale $e^{a}$ & $10-40$ & 96 & 20 & $16-22$ \\
\hline Acceptance of illness scale & $8-40$ & 222 & 27 & $21-33$ \\
\hline Perceived stress scale ${ }^{\circ}$ & $0-56$ & 96 & 25 & $18-31$ \\
\hline Satisfaction with life scale & $5-35$ & 96 & 18 & $12-27$ \\
\hline \multicolumn{5}{|l|}{ Support } \\
\hline Actual emotional & $0-7$ & 222 & 6 & $5-7$ \\
\hline Ideal emotional & $0-7$ & 222 & 7 & $6-7$ \\
\hline Actual practical & $0-7$ & 222 & 6 & $4-7$ \\
\hline Ideal practical & $0-7$ & 222 & 6 & $5-7$ \\
\hline Emotional discrepancy ${ }^{2}$ & $0-7$ & 222 & 0.2 & $0-0.8$ \\
\hline Practical discrepancy & $0-7$ & 222 & 0.3 & $0-2$ \\
\hline Professional support & $0-6$ & 222 & 3 & $1-5$ \\
\hline
\end{tabular}

CECS, Courtauld Emotional Control Scale; EADL, Extended Activities of Daily Living Scale; HLC, Multidimensional Health Locus of Control.

Indicates where high score is bad. 
Table 2 Variable relationships with carer strain

\begin{tabular}{|c|c|c|}
\hline \multirow[b]{2}{*}{ Variable } & \multicolumn{2}{|c|}{ Carer Strain Index } \\
\hline & $n$ & $r^{\circ}$ \\
\hline Age of patient & 222 & -0.003 \\
\hline Days since stroke & 222 & -0.03 \\
\hline London Handicap & 222 & $-0.38 * \cdots$ \\
\hline Occupation & 222 & $0.40 * \cdots$ \\
\hline Orientation & 222 & $0.23 \cdots$ \\
\hline Independence & 222 & $0.28 * *$ \\
\hline Mobility & 222 & $0.36 * *$ \\
\hline $\begin{array}{l}\text { Economic } \\
\text { Self-sufficiency }\end{array}$ & 222 & $0.37 * *$ \\
\hline Social integration & 222 & $0.32 * \cdots$ \\
\hline Patient EADL & 222 & $-0.51 \cdots$ \\
\hline Kitchen & 222 & $-0.47^{* *}$ \\
\hline Domestic & 222 & $-0.44 * \cdots$ \\
\hline Mobility & 222 & $-0.46 * \cdots$ \\
\hline Leisure & 222 & $-0.39 * \cdots$ \\
\hline Carer GHQ-12 & 222 & $0.51 \cdots$ \\
\hline Patient GHO-12 & 222 & $0.47 \cdots$ \\
\hline Internal HLC & 96 & 0.06 \\
\hline Chance HLC & 96 & $0.21^{*}$ \\
\hline Powerful HLC & 96 & 0.09 \\
\hline CECS total expressivity & 96 & 0.18 \\
\hline CECS anger & 96 & 0.11 \\
\hline CECS depression & 96 & $0.20^{*}$ \\
\hline CECS fear & 96 & 0.15 \\
\hline Life Orientation Test & 96 & $-0.32 * \cdots$ \\
\hline PANAS Negative Affectivity & 96 & $0.56 * \cdots$ \\
\hline PANAS Positive Affectivity & 96 & $-0.26 *$ \\
\hline Self-esteem scale & 96 & $0.28^{* *}$ \\
\hline Acceptance of illness scale & 222 & $-0.36 * \cdots$ \\
\hline Perceived stress scale & 96 & $0.42 * *$ \\
\hline Satisfaction with life scale & 96 & $-0.43 * \cdots$ \\
\hline Actual emotional support & 222 & $-0.22 * \cdots$ \\
\hline Ideal emotional support & 222 & -0.12 \\
\hline Actual practical support & 222 & $-0.25 * \cdots$ \\
\hline Ideal practical support & 222 & -0.13 \\
\hline Emotional discrepancy & 222 & $0.23 * \cdots$ \\
\hline Practical discrepancy & 222 & $0.28 * \cdots$ \\
\hline Professional supoort & 222 & $0.21^{*}$ \\
\hline
\end{tabular}

EADL, Extended Activities of Daily Living Scale; HLC, Multidimensional Health Locus of Control; CECS, Courtauld Emotional Control Scale.

${ }^{*} p<0.05,{ }^{*} p<0.01,{ }^{* *} p<0.001$. 
Table 3 Factors predictive of strain in co-resident spouse carers

\begin{tabular}{lrlrlrr}
\hline Strain & \multicolumn{1}{c}{$B$} & SE & df & Sig & \multicolumn{1}{l}{$R$} & $\exp (B)$ \\
\hline Carer GHQ-12 & 0.30 & 0.09 & 10.22 & 0.001 & 0.25 & 1.35 \\
Patient EADL & -0.13 & 0.05 & 7.58 & 0.01 & -0.21 & 0.88 \\
Negative affectivity & 0.08 & 0.03 & 5.15 & 0.02 & 0.16 & 1.08 \\
Constant & -2.05 & 0.82 & 6.28 & & & \\
\hline
\end{tabular}

EADL, Extended Activities of Daily Living Scale. B, unstandardized coefficient; SE, standard error; df, degrees of freedom; Sig, significance value; $R$, regression coefficient; exp $(B)$, exponential $(B)$. 
Table 4 Distribution of scores on individual items of the Caregiver Strain Index

\begin{tabular}{|c|c|c|c|c|}
\hline Item on CSI & Strained & Not strained & $x^{2}$ & p-value \\
\hline \multicolumn{5}{|c|}{ Disturbed sleep } \\
\hline Yes & $57(70 \%)$ & $45(32 \%)$ & \multirow[t]{2}{*}{29.09} & \multirow[t]{2}{*}{$<0.001$} \\
\hline No & $25(30 \%)$ & $95(68 \%)$ & & \\
\hline \multicolumn{5}{|c|}{ Patient has changed } \\
\hline Yes & $70(80 \%)$ & $50(36 \%)$ & \multirow[t]{2}{*}{51.33} & \multirow[t]{2}{*}{$<0.001$} \\
\hline \multirow{2}{*}{\multicolumn{5}{|c|}{ Work adjustment }} \\
\hline & & & & \\
\hline $\begin{array}{l}\text { Yes } \\
\text { No }\end{array}$ & $22(27 \%)$ & $9(6 \%)$ & 17.91 & $<0.001$ \\
\hline \multicolumn{5}{|c|}{ Financial strain } \\
\hline Yes & $61(74 \%)$ & $29(21 \%)$ & \multirow[t]{2}{*}{61.81} & \multirow[t]{2}{*}{$<0.001$} \\
\hline No & $21(26 \%)$ & $111(79 \%)$ & & \\
\hline \multicolumn{5}{|c|}{ Feeling overwhelmed } \\
\hline Yes & $69(84 \%)$ & $40(29 \%)$ & \multirow[t]{2}{*}{63.91} & \multirow[t]{2}{*}{$<0.001$} \\
\hline No & $13(16 \%)$ & $100(71 \%)$ & & \\
\hline \multicolumn{5}{|l|}{ Inconvenient } \\
\hline Yes & $52(63 \%)$ & $24(17 \%)$ & \multirow[t]{2}{*}{49.18} & \multirow[t]{2}{*}{$<0.001$} \\
\hline No & $30(37 \%)$ & $116(83 \%)$ & & \\
\hline \multicolumn{5}{|l|}{ Physical strain } \\
\hline Yes & $45(55 \%)$ & $14(10 \%)$ & \multirow[t]{2}{*}{53.37} & \multirow[t]{2}{*}{$<0.001$} \\
\hline No & $37(45 \%)$ & $126(90 \%)$ & & \\
\hline \multicolumn{5}{|l|}{ Confining } \\
\hline Yes & $71(87 \%)$ & $33(24 \%)$ & \multirow[t]{2}{*}{82.46} & \multirow[t]{2}{*}{$<0.001$} \\
\hline No & $11(13 \%)$ & $107(76 \%)$ & & \\
\hline \multicolumn{5}{|c|}{ Family changes } \\
\hline Yes & $58(71 \%)$ & $13(9 \%)$ & \multirow[t]{2}{*}{89.75} & \multirow[t]{2}{*}{$<0.001$} \\
\hline No & $24(29 \%)$ & $127(91 \%)$ & & \\
\hline Changes in $p$ & & & & \\
\hline Yes & $66(81 \%)$ & $44(31 \%)$ & 49.79 & $<0.001$ \\
\hline No & $16(19 \%)$ & $96(69 \%)$ & & \\
\hline Other deman & & & & \\
\hline Yes & $38(46 \%)$ & $20(14 \%)$ & 27.53 & $<0.001$ \\
\hline No & $44(54 \%)$ & $120(86 \%)$ & & \\
\hline Emotional adj & & & & \\
\hline Yes & $58(71 \%)$ & $21(15 \%)$ & 70.07 & $<0.001$ \\
\hline No & $24(29 \%)$ & $119(85 \%)$ & & \\
\hline Upsetting bel & & & & \\
\hline Yes & $63(77 \%)$ & $37(26 \%)$ & 53.07 & $<0.001$ \\
\hline No & $19(23 \%)$ & $103(74 \%)$ & & \\
\hline
\end{tabular}


